\title{
Situação de crise psíquica e desejo de saber*1
}

\author{
Helena Maria Melo Dias*2 \\ Paulo Roberto Ceccarelli*3 \\ Ana Cleide Guedes Moreira*4
}

Este artigo, resultado de uma pesquisa de pós-doutorado, aborda a noção de crise psíquica em Pierre Fédida. Articula-se ao caso de uma paciente com HIV-AIDS, hospitalizada, cujos efeitos contratransferenciais da psicoterapia fazem pensar nos processos críticos da situação de crise psíquica e no desejo de "saber de si". A escuta analítica possibilitou o saber de si. Considera-se que a noção de crise psíquica contribui com a investigação sobre a psicoterapia psicanalítica no hospital.

Palavras-chave: Crise psíquica, contratransferência, desejo de saber, psicoterapia psicanalítica no hospital

*1 Trabalho inserido no Projeto de Pesquisa "Relações de gênero, feminismos, sexualidade, vulnerabilidade: feminização da epidemia do HIV/aids", coordenado pela Profa. Dra. Ana Cleide Guedes Moreira (CNPq, processos n. 404921/2012-4).

*2 Universidade do Estado do Pará - UEPA (Belém, PA, Br).

*3 Pontifícia Universidade Católica de Minas Gerais - PUC-Minas (Belo Horizonte, $\mathrm{MG}, \mathrm{Br}$ )

${ }^{* 4}$ Universidade Federal do Pará - UFPA (Belém, PA, Br). 


\section{ARTIGO}

\section{Introdução}

Este trabalho, resultado da pesquisa realizada no pós-doutorado em psicologia, pela primeira autora, aborda pontos já desenvolvidos anteriormente na sua tese que sustenta a relevância da contratransferência no dispositivo clínico psicanalítico (Dias, 2007). Nessa tese, Dias (2007) considera que a elaboração da contratransferência em Fédida amplia a concepção metapsicológica da técnica, ao considerar esta como correlativa da metapsicologia dos processos psíquicos do analista, e não a pessoa do analista. A manifestação contratransferencial como algo do erótico do analista, que, segundo Freud (1910), deve ser controlado, dominado, equivale, em Fédida (1988), a um "dispositivo inerente à situação analítica e adequado ao enquadre do tratamento" (p. 71).

Retoma-se esta tese (Dias, 2007) para refletir sobre a noção de crise psíquica, tal como entendida por Fédida (1992), ressaltando sua relevância na clínica psicanalítica em hospital. Para isso, parte-se da concepção freudiana da técnica psicanalítica.

\section{Técnica psicanalítica}

Em 1900, Freud escreve sua tese máxima $A$ interpretação dos sonhos, obra que, juntamente com os "Três ensaios sobre a teoria da sexualidade" (Freud, 1905/1980b), figuram, sem dúvida, como as contribuições mais significativas e originais de Freud para o conhecimento humano. O Livro dos Sonhos tornou-se, para ele, a peça central de sua obra. Na verdade, a mola mestra de todas as descobertas freudianas na construção da psicanálise, na sua compreensão das diferentes psicopatologias e na especificidade de sua técnica psicoterápica. No dizer de Freud, esse livro contém "a mais valiosa de todas as descobertas que tive a felicidade de fazer. Um discernimento claro como esse só acontece uma vez na vida" (Freud, 1900/1980a, p. 38). 
Freud parte do exame minucioso da exigência psíquica para associar, transferir, deslocar, condensar, sobredeterminar, regredir, e analisa a dinâmica dos processos que envolvem a elaboração onírica, do ponto de vista dinâmico, econômico e tópico do funcionamento do aparelho psíquico. Ele observou que, no quadro clínico da neurose, esses processos se intensificam devido ao conflito entre os diferentes sistemas psíquicos. Essa dinâmica produz um alto dispêndio de energia que leva o aparelho psíquico a estabelecer uma formação de compromisso entre os diferentes sistemas, dando origem ao sintoma.

A especificidade da técnica psicanalítica está fundamentada nos seguintes teoremas freudianos: o primeiro, de acordo com o qual "quando se abandonam as representações-meta conscientes, as representações-meta ocultas (inconscientes) assumem o controle do fluxo de representações" (Freud, 1900/1980a, p. 487); e o segundo, o qual afirma que "as associações superficiais são apenas substitutos, por deslocamento, de associações mais profundas e suprimidas" da consciência (p. 487). Para Freud, "a rigor esses teoremas transformaram-se em pilares básicos da técnica psicanalítica” (p. 487).

Esses pilares permitem-lhe estabelecer a regra fundamental do processo terapêutico, na qual o analista deve manter uma escuta com atenção flutuante à fala associativa do paciente, ou seja, o paciente deve falar tudo que lhe vier à cabeça, sustentado no processo transferencial. Essa regra fundamenta a máxima liberdade de expressão do paciente, que pode, e deve, falar sem nenhuma censura tudo o que lhe vem ao pensamento durante o processo analítico. Ao paciente é dado dizer o que sabe, mas especialmente o que não sabe sobre si, ou seja, seus pensamentos inconscientes tendem a se manifestar, revelando, nos tropeços da linguagem, as falhas do saber.

O modo como o analista escuta não é ingênuo, baseia-se na escuta flutuante que oscila entre o processo primário e o secundário da dinâmica do funcionamento psíquico e é formado por uma longa experiência prévia — que envolve sua análise pessoal, os estudos teóricos, o atendimento clínico e a supervisão. Segundo Mezan (1993),

(...) praticar a escuta psicanalítica - pressupõe um modo de conceber o homem, a alma e a linguagem que não é dado intuitivamente a ninguém (...) é possibilitado por certas hipóteses sobre o funcionamento psíquico - metapsicologia - e sobre a natureza do processo terapêutico - as noções de transferência e resistência. (p. 92)

O fenômeno da transferência é observado desde as primeiras experiências de Freud no campo da clínica psicopatológica. Na sensibilidade clínica, aguçada, de Freud, ele atenta inicialmente uma falsa ligação e a acolhe, para que, junto com a paciente, possa encontrar a verdadeira ligação da representação afetiva que foi recalcada. 


\section{ARTIGO}

Todavia, a transferência, até formalizar-se como conceito, passa por uma longa elaboração, na qual o conteúdo da noção vai se diversificando e se tornando mais complexo. Assim, a conceituação de transferência integra-se ao processo de criação da psicanálise exatamente na articulação entre a prática e a teoria. Sua definição evolui em função da prática clínica, sendo, na verdade, o que determina o processo analítico, e é o mais precioso aliado da terapia, bem como seu maior obstáculo.

A identificação da transferência como operador da análise só foi possível com o estabelecimento da regra fundamental. Dessa perspectiva, Fédida (1991) argumenta que a condição de instauração da situação analítica está referida à condição de linguagem e disso resulta que na técnica analítica "o analista deve, portanto, permanecer impenetrável (undurchsichtig) e, 'como superfície de espelho, não mostrar nada além do que lhe foi mostrado"” (p. 207). Compartilha-se com Fédida (1988) que a referência a esse axioma freudiano torna possível a especificação de que "o que nos faz terapeutas é a existência da regra fundamental em nosso pensamento, assim como de tudo o que se passa entre nós e o paciente como desvios em relação a essa regra ideal" (p. 31).

Em relação a esses desvios à regra fundamental, Freud (1912) é enfático na sua observação dos limites da análise que, naquela época, tinha como paradigma a neurose. Assim, tanto as condições institucionais quanto a aceitação de casos difíceis impuseram o emprego de certos recursos que se afastam do procedimento técnico da regra fundamental. Aliás, tanto isso é verdade que certos casos-limites, na incapacidade em que se encontram de aceitar ou admitir um enquadre estável, obrigam de certa forma o analista a desenvolver com eles maneiras de troca de tipo comunicacional (Fédida, 1992).

$\mathrm{Na}$ prática com os 'casos difíceis', o que se observa é que esses pacientes geralmente estão em busca de todos os meios para aliviar um sofrimento intolerável e se recusam com muita frequência a recorrer ao tratamento medicamentoso. Fédida (1992) admite que esses tratamentos não poderiam ser regrados (tanto do ponto de vista técnico quanto teórico) pelo paradigma freudiano da neurose. Dessa perspectiva, a criação teórico-clínica foi bastante estimulada pelas dificuldades técnicas levantadas nos tratamentos de pacientes difíceis. $\mathrm{O}$ autor afirma que a invenção de novos paradigmas na psicanálise é o resultado de uma "revolução terapêutica". Ele reconhece que

Os inovadores nesse domínio permanecem, em seu conjunto, fiéis à tradição freudiana, mas exploram, baseando-se em seus "fracassos" técnicos, as possibilidades de deslocamento dos pontos de apoio teóricos, de diversificação de suas modalidades de atenção, de se levar em conta funções afastadas da técnica clássica. (p. 206) 
Dessa perspectiva, a técnica psicoterapêutica com pacientes em situação de crise afasta-se da técnica clássica, pois exige intervenções mais diretivas, especialmente com casos em que está presente um processo grave de desorganização do eu, de perdas de referenciais, considerados casos difíceis.

\section{Crise psíquica}

O termo crise, em grego Krisis, designa 'ação ou faculdade de distinguir, decisão, momento decisivo'; em Latin Crisis, 'momento de decisão, de mudança súbita. Na medicina, 'momento que define a evolução de uma doença para a cura ou para a morte'. (Dicionário Hoauiss online)

Gondim (2007) especifica em sua tese que a crise psíquica grave ou surto psíquico caracteriza-se pela experiência de desrealização, despersonalização e perda de alteridade: o eu, o outro se confundem, assim como mundo interno e mundo externo; há uma ruptura na experiência do tempo consensual misturando-se passado, presente e futuro, e uma fragmentação do mundo interno, que passa a ser invadido por intensos afetos.

Essa dimensão de uma intensidade afetiva presente na vivência da crise é reconhecida por diversos psicanalistas, dentre os quais, McDougall (1996) que, ao tratar sobre a função integrativa psique-soma proveniente das relações iniciais entre mãe e filho, dá ênfase às primeiras trocas desse par no surgimento do que chama de soluções psicossomáticas. Observa que a mãe pode não ser capaz de atender às necessidades do filho por entraves internos ou questões ambientais. Esse fato criaria no bebê um sentimento permanente de frustração e fúria impotente. Esse tipo de experiência poderia impeli-lo a "construir com os recursos de que dispõe maneiras radicais de se proteger de crises afetivas e do esgotamento que disso pode resultar" (p. 39). Para a autora, esse modo de proteção estaria mais ligado ao uso de defesas primitivas contra a emoção, mas muito mais direcionadas ao fenômeno psicossomático que psicótico, em alguns casos.

Fédida (1992), em seu complexo artigo "Crise e metáfora", reconhece o fato de a noção de crise remeter-se teoricamente bem pouco à psicanálise, mas, a partir da importância atribuída em psicoterapia a situações de crise, deseja chamar a atenção para o interesse que, na psicanálise, poderá tomar esta noção - a de crise - bastante alheia a seu campo. Entende-se esse alheamento advindo da rigorosa e sistemática formulação teórica freudiana do aparelho psíquico, a qual tem como paradigma o sonho e a elaboração técnica da regra fundamental de investigação do inconsciente no tratamento. No entanto, essa técnica não é apropriada na intervenção da crise. 


\section{ARTIGO}

Fédida (1992) observa o quanto é notável que, de alguns anos para cá, as referências diferenciadas ao "modelo psicanalítico da crise" vêm multiplicando-se. Para o autor:

Esses trabalhos explicitam - com frequência em função das psicoterapias dos estados-limites — um modelo psicanalítico amplamente inspirado pela ideia de reativação das vivências traumáticas infantis pelos acontecimentos atuais, pela teoria dos conflitos intrapsíquicos, pelo modelo da experiência do desamparo primitivo quando faltam do interior ou do exterior respostas adequadas próprias a resolver intoleráveis tensões (ação específica). (p. 216; grifo do autor)

A palavra "crise" recobre o fenômeno da angústia em relação ao eu, o excesso de excitações insuportáveis para o aparelho psíquico, as constantes rupturas provocando bruscos remanejamentos econômicos, colocando em risco a vida do indivíduo; essa palavra teria então um amplo alcance de apelação, sem verdadeiro poder de denominação conceitual. Fédida (1992) entende a noção de crise como um processo crítico. Para ele, trata-se então de se servir deste como um conceito clínico-técnico descritivo do dispositivo pré-consciente da contratransferência. A riqueza desse recurso depende da receptividade do analista ao detalhe e da ressonância dessa observação na construção metafórica da interpretação. Tal sensibilidade permite não somente discernir as variações da vida psíquica do paciente, mas também as modificações das disposições internas do analista de instaurar e reinstaurar a situação analítica. Por conseguinte, evidencia-se uma definição de contratransferência em termos de regulação econômica das trocas intrapsíquicas e de paraexcitação que o aparelho comporta idealmente.

Fédida (1992) observa: "de fato, poderíamos acrescentar que, do ponto de vista teórico, esse conceito de processo crítico serve sem dúvida muito melhor à atividade de modelização no projeto de uma psicopatologia fundamental que à teorização psicanalítica stricto sensu" (p. 218; grifos do autor). Entende-se com o autor que o campo da psicopatologia fundamental congrega diferentes saberes sobre o pathos psíquico que não pode ser limitado a uma única leitura. Nas palavras de Paulo Roberto Ceccarelli (2005),

A preocupação central da Psicopatologia Fundamental é de contribuir para a redefinição do campo do psicopatológico. Ela propõe uma reflexão crítica dos modelos existentes e uma discussão dos paradigmas que afetam nossos objetos de pesquisa, nossas teorias e nossas práticas. A Psicopatologia Fundamental reconhece e dialoga com outras leituras presentes na polis psicopatológica. (pp. 373-374)

Quanto a situações de crise, Fédida (1992) adverte para o fato de que elas exigem previamente do analista uma avaliação adequada de sua viabilidade psíquica com o caso, necessidades eventuais de colaboração terapêutica (apoios 
medicamentosos, eventualidade de hospitalizações, envolvimento dos próximos), enfim, tempo pessoal que lhe deverá ser dedicado por longos períodos.

$\mathrm{Na}$ dinâmica contratransferencial, o analista deve tomar em consideração suas próprias reações íntimas àquilo que o paciente lhe comunica, como inerente à situação analítica e adequada ao enquadre do tratamento (Dias e Berlinck, 2011).

Por isso, entende-se que esse dispositivo clínico se mantém independente do espaço em que ocorra a análise, se no consultório particular ou num espaço social. Todavia, é impossível não reconhecer que no ambiente hospitalar as condições de tratamento psicanalítico são inteiramente diferentes da clínica privada. Levy e Moreira (2008) argumentam que "nos atendimentos ambulatoriais e hospitalares, a dinâmica transferencial se especifica, demandando do analista, formas de atuação diferentes, ampliando a clínica tradicional” (p. 46).

Portanto, na clínica hospitalar trabalha-se com a psicanálise e a psicopatologia fundamental. Nessa leitura teórico-clínica, constrói-se o caso Clara, o qual norteia nossas reflexões sobre os processos críticos da situação de crise psíquica e no desejo de "saber de si", num momento de grande desorganização psíquica.

\section{A escuta do desejo de saber de Clara}

Clara constatou sua infecção pelo HIV-AIDS durante o exame pré-natal. Após o impacto traumático do diagnóstico, estabeleceu para si um rígido sistema de vigilância e de autocontrole a fim de evitar a transmissão do vírus para seu filho, bem como no intuito de evitar que seus familiares e conhecidos tomassem conhecimento de sua infecção. Mudou-se com o marido para uma nova residência bem distante dos familiares e com poucos vizinhos ao redor, mantendo-se num isolamento social. Falava demarcando uma vivência cindida entre sua vida antes do diagnóstico de HIV-AIDS positivo e depois, que demarcava o efeito traumático do diagnóstico.

A noção de trauma psíquico remete à concepção econômica no sentido de dispêndio excessivo de energia psíquica, pois, conforme Laplanche e Pontalis (1991), é:

(...) uma vivência que, no espaço de pouco tempo, traz um aumento de excitação à vida psíquica, que a sua liquidação ou sua elaboração pelo meios normais e habituais fracassa, o que não pode deixar de acarretar perturbações duradouras no funcionamento energético. (p. 523)

No sistema defensivo, Clara cumpriu firme o tratamento medicamentoso, comparecendo mensalmente à unidade de saúde para controle da infecção e seu 


\section{ARTIGO}

filho não foi contaminado pelo HIV. Após a vivência traumática, ela manteve o rígido autocontrole durante aproximadamente cinco anos, quando então um novo dado da realidade - o falecimento do seu genitor - invadiu-a violentamente, e sua rigidez disciplinar foi quebrada. Considerou-se aquele como um momento de crise, que operou uma profunda desorganização psíquica em decorrência dessa perda. Clara deixou de tomar os antirretrovirais e ficou exposta a doenças oportunistas. Bastante enfraquecida e debilitada, foi internada no hospital.

A evolução médica do quadro clínico era instável, ora melhorava, ora piorava. Esse real da dor, essa instabilidade na evolução do tratamento a atormentava. Sabe-se com Freud (1914/1980d) que uma pessoa atormentada por dor e mal-estar orgânico deixa de se interessar pelas coisas do mundo externo, e "retira o interesse libidinal de seus objetos amorosos: enquanto sofre deixa de amar" (p. 98).

Entretanto, o fato de os pacientes deixarem de amar no momento da doença não exclui a necessidade de ser amado, pois este é o sentimento que faz o enfermo sentir-se protegido e que pode acalentá-lo diante da situação de desamparo instalado pela doença. Por isso, precisa do amor, do apoio do outro, como uma forma de compensação por aquilo que a doença lhe tirou. $\mathrm{O}$ amor do outro é o amparo diante da situação de desamparo instalada pela doença (Cedaro, 2005).

A evolução psicoterapêutica de Clara surpreendeu-me pela urgência dos processos psíquicos ativados. Falava ininterruptamente, revelando uma dissociação interna muito desorganizadora e angustiante. Uma angústia como um sinal de alarme! Nesse quadro clínico, as intervenções foram direcionadas no sentido do desvendamento dessa sinalização para restituir-lhe certa organização interna, como também seu vínculo com o ambiente. Nesse estado, Clara expressou de modo veemente seu desejo de falar. Às vezes não conseguia falar devido ao estado de intensa dor, mas, à medida que se sentia um pouco aliviada, desabrochava a falar de modo quase ininterrupto, trazendo suas dores psíquicas, com sentido de apelo.

$\mathrm{Na}$ contratransferência, observei sua dinâmica psíquica num movimento oscilatório de uma linguagem enquanto descarga afetiva e uma fala reflexiva, com insight. Em um dado momento próximo à sua alta hospitalar, Clara me interrogou: "Doutora, quando eu tiver alta, eu posso continuar sendo atendida aqui? Tenho tanta coisa para falar!". Surpreendi-me com seu discernimento desse lugar, um lugar que promove um maior conhecimento de si. E parecia tratar-se disso, desse desejo de saber de si, pois vivenciava uma crise que lhe exigia fala e um destinatário que acolhesse esse apelo.

Freud identificava o desejo de saber como o desejo de ir em busca de um saber sexual. Em "Três ensaios sobre a teoria da sexualidade" (1905/1980b), ele diz:

a vida sexual da criança chega a sua primeira florescência, entre os três e os cinco anos, também se inicia nela a atividade que se inscreve na pulsão de saber ou de 
investigar. Essa pulsão não pode ser computada entre os componentes pulsionais elementares, nem exclusivamente subordinada à sexualidade. (p. 182)

Apesar disso, reconhece que as primeiras inquietações do pensamento advêm da curiosidade sexual infantil. São questões que permeiam o intelecto infantil que dizem respeito às origens: de onde vêm os bebês? Por que a diferença sexual? O que eu represento no desejo de meus pais? Dentre outras. Para Freud (1900/1980a), desde 1900, "nada senão o desejo pode colocar nosso aparelho anímico em ação" (p. 517).

$\mathrm{Na}$ última sessão, Clara havia tomado banho e estava sentada na cama escovando os cabelos e escutando música. Nessa sessão, ela falou especialmente dos efeitos do diagnóstico de HIV-AIDS positivo. O tema sobre os efeitos do diagnóstico foi constante durante a psicoterapia, todavia, nessa sessão ela revive, com toda intensidade afetiva, seu medo de morrer, de ser abandonada, a cisão interna provocada pelo trauma. Clara, à medida que rememorou afetivamente sua vivência traumática, pôde realizar seu desejo de saber de si — uma reconstituição de um eu, de existência própria, originária da infância. Esse reinvestimento narcísico deu suporte a um cuidar de si.

O trabalho clínico com Clara trouxe importantes ensinamentos, dentre esses, a possibilidade de pensar um desfecho positivo da experiência da crise. Dessa perspectiva, compartilha-se com o argumento de Ávila e Berlinck (2014), que diz:

Mediante uma crise o indivíduo será convocado a mobilizar seus recursos psíquicos, o que lhe dará a oportunidade de poder se exercitar no reconhecimento do seu potencial. Neste aspecto, a crise não representa um fator negativo, já que pode propiciar o desenrolar de um processo criativo, de autonomia, mediante novas perspectivas e até um reposicionamento subjetivo. No entanto, é comum a ocorrência de uma sensação de desordem desencadeada por este processo. (p. 272)

A psicanálise freudiana valorizou o amor de transferência como sustentáculo do processo analítico que, no caso Clara, permitiu-lhe ativar sua autoerótica e seu narcisismo, com a desinibição ao prazer autoerótico e aloerótico.

\section{Considerações finais}

O trabalho clínico com Clara operou um rearranjo subjetivo ao tratar sua questão de saber de si, em face da crise psíquica desorganizadora e angustiante. Aprendemos com a psicanálise que o desejo se presentifica no sintoma, uma vez que foi desalojado pelo recalque e que a força do desejo repousa justamente na pulsão sexual. O sujeito deve encontrar seu próprio modo de lidar com o apelo desse desejo para libertar-se rumo à satisfação. 


\section{ARTIGO}

Essa clínica corrobora com as investigações que acentuam o valor da psicanálise como prática da escuta, num espaço distinto da análise clássica, embora $\mathrm{o}$ discurso cientificista que opera na atualidade tente anular a subjetividade, isto é, a singularidade do sujeito.

\section{Referências}

Ávila, C.S. \& Berlinck, M.T. (2014, dezembro). Reflexões sobre crise e estabilização em psicopatologia Fundamental. Tempo Psicanalítico, Rio de Janeiro, 46(2), 270-286.

Cedaro, J.J. (2005). A ferida na alma: os doentes de AIDS sob o ponto de vista psicanalítico. (Tese de Doutorado em Psicologia). Instituto de Psicologia. Universidade de São Paulo, - USP, São Paulo.

Ceccarelli, P.R. (2005, set./out). Sofrimento psíquico na perspectiva da Psicopatologia Fundamental. Psicologia em Estudo, Maringá, 10(3), 471-477.

Dias, H.M.M. (2007). Contratransferência: um dispositivo clínico psicanalítico. (Tese Doutorado em Psicologia Clínica). Pontifícia Universidade Católica de São Paulo/ PUC-SP, São Paulo.

Dias, H.M.M. \& Berlinck, M.T. (2011, dezembro). Contratransferência e enquadre analítico em Pierre Fédida. Revista Psicologia Clínica, Rio de Janeiro, 23(2), 221-231.

Fédida, P. (1988). Clínica psicanalítica: estudos. Trad. Cláudia Berliner. São Paulo: Escuta.

Fédida, P. (1991). Nome, figura e linguagem. São Paulo: Escuta, 1991.

Fédida, P. (1992). Crise e Metáfora. In: Crise et Contre-transfert. Tradução Martha Gambini. Presses Universitaires de France (inédito em português).

Freud, S. (1970). As perspectivas futuras da terapêutica psicanalítica. In Edição Standard Brasileira das Obras Psicológicas Completas de Sigmund Freud. Rio de Janeiro: Imago. (Trabalho publicado originalmente em 1910).

Freud, S. (1980a). A interpretação de sonhos. In Edição Standard Brasileira das Obras Psicológicas Completas de Sigmund Freud. Rio de Janeiro: Imago. (Trabalho publicado originalmente em 1900).

Freud, S. (1980b). Três ensaios sobre a teoria da sexualidade. In Edição Standard Brasileira das Obras Psicológicas Completas de Sigmund Freud. Rio de Janeiro: Imago. (Trabalho publicado originalmente em 1905).

Freud, S. (1980c). Recomendações aos médicos que exercem a psicanálise. In Edição Standard Brasileira das Obras Psicológicas Completas de Sigmund Freud. Rio de Janeiro: Imago. (Trabalho publicado originalmente em 1912).

Freud, S. (1980d). Introdução ao narcisismo. In Edição Standard Brasileira das Obras Psicológicas Completas de Sigmund Freud. Rio de Janeiro: Imago. (Trabalho publicado originalmente em 1914). 
Gondim, M.F.N. (2007). Os sentidos dos vínculos na crise psíquica grave. (Tese de Doutorado) Universidade Nacional de Brasília - UNB, Brasília.

Laplanche, J. \& Pontalis, J-B. (1991). Vocabulário de psicanálise. São Paulo: Martins Fontes.

Levy, E.S. \& Moreira, A.C.G. (2008). Desamparo, transferência e hospitalização: um estudo sobre o paciente internado em centro de terapia intensiva. In A. Pimentel; A.C.G. Moreira (Orgs.), Psicologia, Instituição, cultura. Belém: Amazônia.

McDougall, J. (1996). Teatros do Corpo: o psicossoma em psicanálise. São Paulo: Martins Fontes.

Mezan, R. (1993). O que significa pesquisa em Psicanálise. In M.E.L. da Silva (Org.), Investigações em psicanálise. Campinas: Papirus.

\section{Resumos}

(The psychic crisis situation and the wish do know)

This paper is the result of a post-doctoral research. It debates the notion of psychic crisis according to Pierre Fédida. The authors discuss the case of a hospitalized HIV/AIDS patient, in which the countertransference effects of psychotherapy suggest the critical processes of the psychic crisis situation and the desire to "know about oneself". The analytical process enabled the patient to do so. The paper considers that the notion of psychic crisis contributes to research concerning psychoanalytic psychotherapy in the hospital.

Keywords: Psychic crisis, countertransference, desire to know, psychoanalytic psychotherapy in the hospital

(Situation de crise psychique et désir de savoir)

Cet article, résultat d'une recherche postdoctorale, aborde la notion de crise psychique selon Pierre Fédida. Il s'agit du cas d'une patiente atteinte du VIH/SIDA, hospitalisée, dont les effets contre-transférentiels de la psychothérapie font penser aux processus critiques de la situation de crise psychique et au désir de "savoir de soi». L'écoute analytique a permis le savoir de soi. On considère que la notion de crise psychique contribue à la recherche sur la psychothérapie psychanalytique à l'hôpital.

Mots-clés: Crise psychique, contre-transfert, désir de savoir, psychothérapie psychanalytique à l'hôpital

(Situación de crisis psíquica y deseo de saber)

Este artículo, resultado de una investigación post-doctoral, aborda la noción 


\section{ARTIGO}

de la crisis psíquica según Pierre Fédida. Se relaciona al caso de una paciente con VIH-SIDA, hospitalizada, en la que los efectos contratransferenciales de la psicoterapia sugieren procesos críticos de la situación de crisis psíquica y el deseo de "saber de sí misma". El proceso de escucha analítica le permitió saber de sí misma. Se considera que la noción de crisis psíquica contribuye a la investigación sobre la psicoterapia psicoanalítica en el hospital.

Palabras clave: Crisis psíquica, contratransferencia, deseo de saber, psicoterapia psicoanalítica en el hospital

(Psychische Krisensituation und der Wunsch, sich selbst zu verstehen)

Dieser Beitrag ist das Ergebnis eines Postdoc Forschungsprojektes, der Pierre Fédidas Begriff der psychischen Krise erörtert, am Beispiel einer mit HIV-Aids infizierten Patientin, die in einem Krankenhaus interniert ist. Die gegenübertragenden Wirkungen der Psychotherapie führten zur Reflexion über die kritischen Prozesse der psychischen Krisensituation und des Wunsches, sich selbst zu verstehen. Das analytische Zuhören ermöglichte es der Patientin, sich selbst zu verstehen. Wir kamen zum Schluss, dass die Definition der psychischen Krise zur Untersuchung der psychoanalytischen Psychotherapie im Krankenhaus beiträgt.

Stichwörter: Psychische Krise, Gegenübertragung, Wissenswunsch, psychoanalytische Psychotherapie im Krankenhaus

心理危机状态和认识自我的欲望。

本论文是作者的博士后研究课题的部分结果。目的是探讨法国心理分析学 家皮埃尔・费迪达 (Pierre Fédida) 有关心理危机的概念。作者考察了一个特殊 病例。病人感染了艾滋病毒HIV-AIDS, 住院治疗。在心理分析疗程中, 在反移 情作用 (contratransferências)下，心理分析师见证了一整个心理危机的过程 和病人 “认识自己” 的欲望。分析师通过聆听病人的叙述, 使得病人实现了解 自我的欲望。作者认为, 研究心理危机的概念有助于心理分析疗法在医院的临 床应用。

关键词：心理危机，移情作用，认知欲望，心理分析疗法在医院的临床。

Citação/Citation: Dias, H.M.M., Ceccarelli, P.R., Moreira, A.C.G, (2016, março). Situação de crise psíquica e desejo de saber. Revista Latinoamericana de Psicopatologia Fundamental, 19(1), 70-83.

Editores do artigo/Editors: Prof. Dr. Manoel Tosta Belinck e Profa. Sonia Leite 
Recebido/Received: 13.1.2015/ 1.13.2015 Aceito/Accepted: 20.3.2015 / 3.20.2015

Copyright: (C) 2009 Associação Universitária de Pesquisa em Psicopatologia Fundamental/ University Association for Research in Fundamental Psychopathology. Este é um artigo de livre acesso, que permite uso irrestrito, distribuição e reprodução em qualquer meio, desde que o autor e a fonte sejam citados / This is an open-access article, which permits unrestricted use, distribution, and reproduction in any medium, provided the original authors and sources are credited.

Financiamento/Funding: Esta pesquisa foi financiada pela Coordenação de Aperfeiçoamento de Pessoal de Nivel Superior - CAPES / This research was funded by Coordenação de Aperfeiçoamento de Pessoal de Nivel Superior - CAPES.

Conflito de interesses/Conflict of interest: Os autores declaram que não há conflito de interesses / The authors have no conflict of interest to declare.

\section{Helena Maria Melo Dias}

Psicóloga; Psicanalista; Professora Adjunto IV da Universidade do Estado do Pará - UEPA

(Belém, PA, Br); Mestrado (2001) e Doutorado (2007), pela Pontifícia Universidade Católica de São Paulo - PUC-SP (São Paulo, SP, Br); Pós-Doutorado na Universidade Federal do Pará - UFPA (Belém, PA, Br); Líder do Grupo do Laboratório de Psicanálise e Psicopatologia Fundamental - LPPF/UFPA (Belém, PA, Br); Líder do Grupo: Subjetividade, afetividade e cuidado em saúde (UEPA/CNPQ) (Belém, PA, Br/ Brasília, DF, Br); Membro da Associação Universitária de Pesquisa em Psicopatologia Fundamental - AUPPF (São Paulo, SP, Br); Pós-Doutorado com auxílio CAPES. Integra Projeto de pesquisa (CNPq: Número do Processo 404921/2012-4), coordenado pela Prof ${ }^{\mathrm{a}}$. Dr ${ }^{\mathrm{a}}$. Ana Cleide Guedes Moreira.

Travessa 14 de abril, 1186/909

66060-460 Belém, PA, Br

e-mail: hmelodias@uol.com.br

\section{Paulo Roberto Ceccarelli}

Psicólogo; Psicanalista; Doutor pela Université de Paris 7 - Diderot (1995) (Paris, Fr), e pós-doutor (Paris VII - 2009); Professor Adjunto IV no Departamento de Psicologia da Pontifícia Universidade Católica de Minas Gerais - PUC-Minas (Belo Horizonte, MG, $\mathrm{Br}$ ); Orientador de Pesquisa e Professor na pós-graduação do Laboratório de Psicanálise e Psicopatologia Fundamental da Universidade Federal do Pará - UFPA (Belém, PA, Br); Orientador de Pesquisa e Professor do Mestrado Profissional de Promoção de Saúde e Prevenção da Violência da Faculdade de Medicina da Universidade Federal de Minas Gerais - UFMG (Belo Horizonte, MG, Br); Membro da Associação Universitária de Pesquisa em Psicopatologia Fundamental (São Paulo, SP, Br); Chercheur associé à l'Université Paris 7 Denis-Diderot; Membro fundador do Réseaux International de 


\section{ARTIGO}

Psychopathologie Transculturelle; Pesquisador do CNPq (Bolsa de Produtividade em Pesquisa) (Processo No: 312687/2013-3).

Rua Rio Grande do Norte, 355/501

30130-131 Belo Horizonte, MG, Br

e-mail:paulocbh@terra.com.br

\section{Ana Cleide Guedes Moreira}

Graduação em Psicologia pela Universidade Federal do Pará - UFPA (1982) (Belém, PA, Br); Mestrado (1992) e Doutorado (2000) em Psicologia Clínica pela Pontifícia Universidade Católica de São Paulo - PUC-SP (São Paulo, SP, Br); Pós-Doutorado em Psicologia Clínica na Universidade Paris 7 (Paris, Fr.); Professora Associada da UFPA; Graduação, Pós-Graduação em Psicologia, (Mestrado); Diretora do Laboratório de Psicanálise e Psicopatologia Fundamental (Belém, PA, Br); Fundadora da Associação Universitária de Pesquisa em Psicopatologia Fundamental (São Paulo, SP, Br); Pesquisadora do Grupo de Estudos e Pesquisas Eneida de Moraes sobre Mulher e Relações de Gênero - UFPA (Belém, PA, Br); Pesquisadora visitante Laboratório Interdisciplinar de Pesquisa e Intervenção Social PUC-Rio (Rio de Janeiro, RJ, Br); Chercheur associé à l' Université Paris 7 Denis-Diderot (Paris, Fr), Fundadora da Réseau Internacional de Psychopathologie Transculturelle.

Projeto de pesquisa (CNPq: Processo n. 404921/2012-4), coordenado pela Prof ${ }^{\mathrm{a}}$. Dr ${ }^{\mathrm{a}}$. Ana Cleide Guedes Moreira.

Av. Augusto Corrêa, 01 66075-900 Belém, PA, Br

e-mail: acleide@uol.com.br

This is an open-access article, which permits unrestricted use, distribution,

(cc) BY-NC and reproduction in any medium for non-commercial purposes provided the original authors and sources are credited. 